\title{
Nuevos documentos relativos al asesinato de la abuela materna de doña Emilia Pardo Bazán
}

\author{
"Grupo de Investigación La Tribuna"1 \\ latribunaepb@realacademiagalega.org
}

(recibido xaneiro/2015, revisado febreiro/2015)

RESUMEN: Damos a conocer nueve documentos desconocidos hasta el momento, cedidos por Carlos de Odriozola, que arrojan nuevos datos sobre el espinoso episodio del asesinato de la abuela paterna de Emilia Pardo Bazán, Joaquina Mosquera, y el posterior suicidio de su segundo marido y asesino, Juan Rey Perfume, tal y como explicamos en un artículo previo del número 8 de la revista La Tribuna. Se trata de cartas y testimonios que amplían la perspectiva, sobre todo la del padre de doña Emilia, acerca de los hechos narrados y documentados en dicho artículo.

PAlAbRAS Clave: Emilia Pardo Bazán, Jose Pardo Bazán, Joaquina Mosquera, Juan Rey Perfume, José María Bermúdez, Luis Guergué.

ABSTRACT: Nine documents unknown until now, provided by Carlos de Odriozola, which give new information on the thorny episode of the murder of Emilia Pardo Bazán's paternal grandmother, Joaquina Mosquera, and the subsequent suicide of her second husband and murderer, Juan Rey Perfume. As was explained in the previous article of no. 8 of the Tribune.There are Letters and testimonies that extend the perspective, especially the one of the father of doña Emilia, about the facts narrated and documented included in that article.

KEY WORDS: Emilia Pardo Bazán, Jose Pardo Bazán, Joaquina Mosquera, Juan Rey Perfume, José María Bermúdez, Luis Guergué.

En el número octavo de la revista La Tribuna ("Grupo de investigación La Tribuna" 2010/2011), este grupo de investigación publicó un documentado artículo sobre el fallecimiento de Joaquina Mosquera a manos de su segundo marido, Juan Rey Perfume, dato prácticamente desconocido por los biógrafos e investigadores de Emilia Pardo Bazán, nieta de doña Joaquina.

Recientemente tuvimos acceso a nuevos documentos relativos a este trágico suceso. Este nuevo material, aunque no modifica las conclusiones de nuestro anterior trabajo, aporta nuevos datos de interés, como los planes de casamiento de don José Pardo Bazán o la negativa del cura rector de la parroquia de Santiago de Betanzos a enterrar en sagrado a Rey Perfume por haberse suicidado.

${ }^{1}$ El "Grupo de Investigación La Tribuna” está formado por Xosé Ramón Barreiro Fernández, Ricardo Axeitos Valiño, Patricia Carballal Miñán y Jacobo M. Caridad Martínez. 
La nueva documentación procede del Archivo de don Carlos de Odriozola Rico-Avello (Madrid). En nuestro artículo previo ya hacíamos constar que Carlos de Odriozola era el único investigador que mencionaba el asesinato de Joaquina Mosquera en un trabajo genealógico sobre los Bermúdez de Castro (Odriozola 2005-2006: 123-228). Efectivamente, en su archivo particular conserva un dossier sobre este hecho elaborado por don José Bermúdez de Castro, quien fue curador de José Pardo Bazán, una copia del cual tuvo la generosidad de facilitarnos recientemente ${ }^{2}$.

Este dossier está formado por una carpetilla en la que se conservan atados diversos documentos, la mayoría posteriores a la muerte de la abuela paterna de Emilia Pardo Bazán. La primera página de guarda tiene escrito a mano el título "Incidencias sobre el fallecimiento de mi cuñada y su marido". A continuación se reúnen varias cartas, recibos, certificados y cuentas fechadas entre 1847 y 1849 . De estos papeles pasamos a transcribir y comentar varios documentos que creemos de interés tanto por permitirnos completar datos ya conocidos como por añadir nueva información.

Antes de describir y comentar la nueva documentación que publicamos, para facilitar su comprensión, vamos a resumir someramente toda la historia que dimos a conocer en nuestro anterior artículo.

En 1839 moría Miguel Pardo Bazán, dejando una viuda, Joaquina Mosquera y un hijo menor de edad, José Pardo Bazán. En atención a la minoría de edad del niño (tenía 12 años) doña Joaquina se hizo cargo, como su curadora y tutora legal, de los bienes que a este le correspondía heredar tras la muerte de su padre.

Años después, en enero de 1847, nació Adelaida Rey Mosquera, fruto de la relación entre Joaquina Mosquera y un joven militar, Juan Rey Perfume. Sin embargo, la pareja no contrajo matrimonio inmediatamente, pues de hacerlo, doña Joaquina perdería automáticamente la administración de las rentas de la herencia de su hijo, quien todavía era menor de edad, y que ascendían a una buena suma para la época. Pero para evitar que una muerte prematura dejase a su nueva hija sin herencia, pues según la legislación de entonces, habiendo hijos legítimos, el hijo natural quedaba excluido de la herencia materna y paterna, inició una serie de movimientos patrimoniales para formar un capital que poder ceder a Adelaida.

Mas en marzo de 1847, José Pardo Bazán, actuando contra los planes de su madre, la destituyó como curadora de sus bienes, nombrando en sustitución a su tío, don José Bermúdez de Castro ${ }^{3}$. Joaquina Mosquera se opuso iniciándose un pleito que se alargó durante meses, hasta que el 7 de octubre de 1847, se casó con Juan Rey, poniendo así fin a la disputa por la curadoría. El nuevo matrimonio, junto a su hija, se instaló en Betanzos, alquilando la casa número 5 de la calle Porta da Cidade.

Finalmente, el 4 de mayo de 1848, Juan Rey Perfume asesinó a su esposa, suicidándose horas después. El asesino dejó una nota en la que, entre otros pormenores, describía una supuesta conspiración alentada por doña Joaquina para asesinar a Luis Guergué, administrador de las rentas que pertenecieron a Miguel Pardo Bazán y al que esta culparía de haber actuado en contra de ella influyendo en su hijo ${ }^{4}$.

El primer documento que transcribimos es una carta de José Pardo Bazán a su tío y curador, don José Bermúdez de Castro, fechada en Santiago de Compostela el 30 de noviembre de 1847. La carta es, pues, posterior a la boda de su madre con Juan Rey y anterior al asesinato. Este documento nos comunica dos datos de relevancia. El primero es la mención que el hijo hace de la "mala fe con que obran" su madre y su pareja y que a sus ojos le autorizaba "a pagar en la misma moneda". Efectivamente, en nuestro trabajo anterior, explicamos el comportamiento de don José Pardo, como resultado del temor a que su madre se aprovechase de su papel como su curadora para sustraer bienes de las rentas de su herencia a favor de su hermanastra.

\footnotetext{
${ }^{2}$ Desde estas páginas reiteramos nuestro agradecimiento a don Carlos de Odriozola por su amabilidad, sin la cual este trabajo no habría sido posible. ${ }^{3}$ Estaba casado con María del Carmen Mosquera, hermana de doña Joaquina. En el trabajo de Carlos de Odriozola (2005-2006), se pueden encontrar datos biográficos de don José Bermúdez y de su familia.
}

${ }^{4}$ Para una exposición detallada de toda esta historia remitimos a nuestro trabajo anterior, "Grupo de investigación La Tribuna" (2010/2011). 
El otro dato, desconocido hasta ahora, es que Pardo Bazán consideró como posibilidad contraer matrimonio, pues los menores de más de 18 años (el tenía 20), al casarse accedían a la administración de sus bienes pudiendo apartar a sus curadores. Sin embargo, todo indica que su tío, José Bermúdez, le convenció para no hacerlo ${ }^{5}$. Aún así, y después de la boda de su madre, que como ya dijimos solucionaba el pleito, seguía temiendo que una muerte prematura convirtiese a su hermana, ahora ya legitimada como tal, en heredera de sus propiedades, confirmando de nuevo esta determinación su disgusto con la madre y su nueva familia.
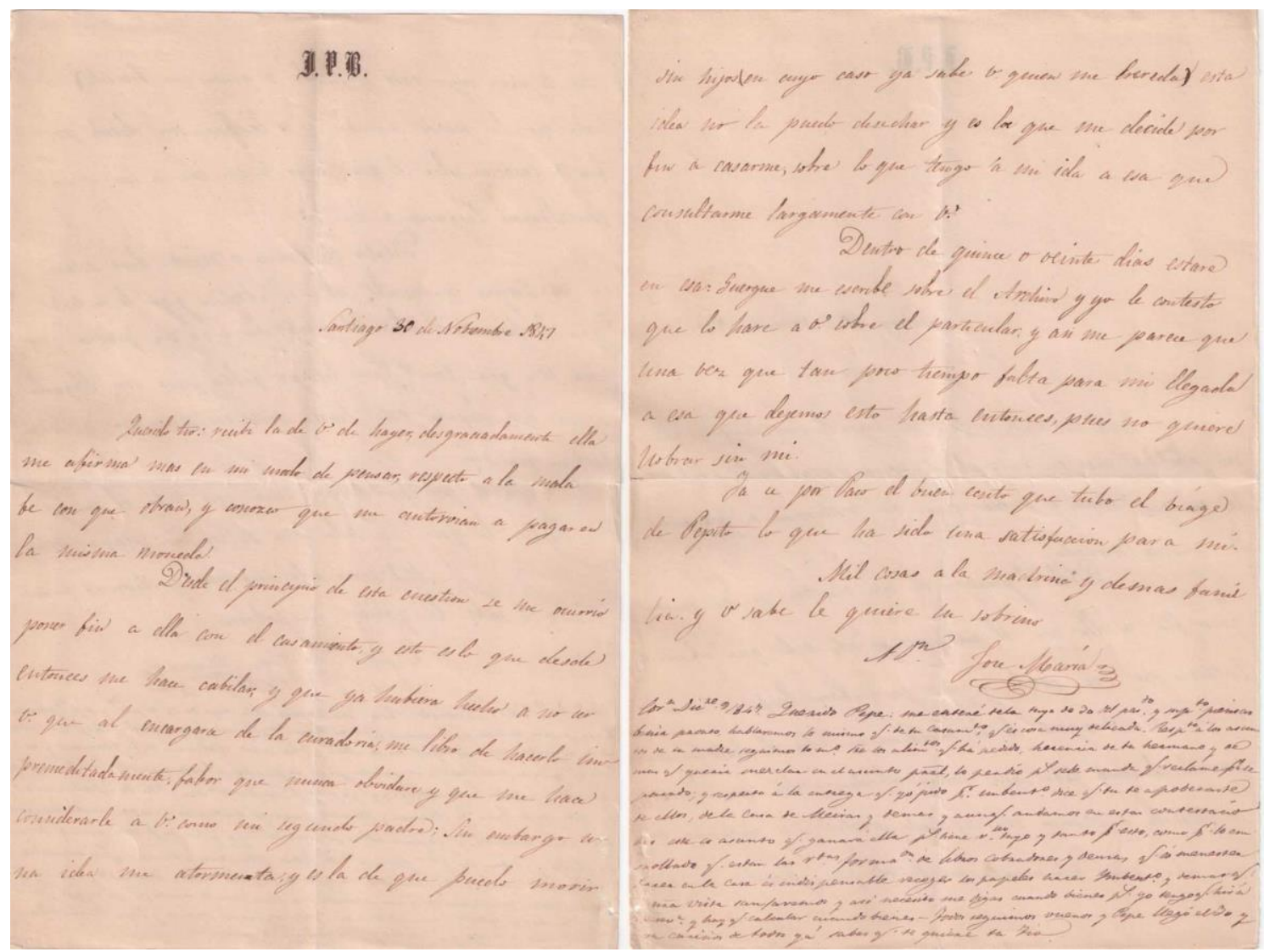

El segundo documento es una carta de José María García, procurador del juzgado de Betanzos, dando noticia del asesinato y suicidio el mismo día del suceso. Aunque no tiene el nombre del destinatario, por el contexto suponemos que se trataba de Luis María Guergué.

Los documentos tres a seis son cartas remitidas a José Bermúdez de Castro en el mes de mayo de 1848 por aquellas personas allegadas a la familia que se encargaron de tramitar en Betanzos todo lo relativo al entierro de la pareja y el arreglo de la casa y los bienes que ésta allí tenía. Esta correspondencia nos aporta otra novedad: la negativa del cura de la iglesia de Santiago de Betanzos, parroquia a la que pertenecían los difuntos, a enterrar en sagrado al suicida Juan Rey Perfume. Finalmente, el asunto se resolvió con la intervención del auditor militar que forzó, Guardia Civil mediante, el entierro de la pareja realizado el día 7 de mayo.

El séptimo documento es la copia simple de una declaración de José Bermúdez sobre su relación con Juan Rey Perfume. Suponemos que esta se produjo dentro de las diligencias abiertas por la auditoría de guerra para esclarecer el asesinato. La intervención de la justicia militar estaba justificada en este caso por el estatus militar del asesino ${ }^{6}$.

Este testimonio nos informa del carácter violento e inestable de Juan Rey el que además estaría dotado de un excesivo sentido del honor. Ya en las conclusiones de nuestro anterior trabajo nos referimos, precisamente,

\footnotetext{
${ }^{5}$ Recordemos que José Pardo Bazán se casó con Amalia de la Rúa en A Coruña en 1850, naciendo al año siguiente su única hija, Emilia Pardo Bazán. ${ }^{6}$ Conocemos el inicio de este expediente gracias a las partidas de defunción de Joaquina Mosquera y Juan Rey ("Grupo de investigación La Tribuna" 2010/2011: 50-51). En su momento nuestro grupo de investigación intentó localizar esta documentación sin éxito.
} 
a esta concepción que del honor tenía Juan Rey como una de las claves de su comportamiento, funcionando a sus ojos como principio legitimador de su conducta ("Grupo de investigación La Tribuna" 2010/2011: 40).

Otro elemento interesante de esta declaración es la alusión a la conspiración de asesinato contra Guergué, cuyos extremos, tal y como aparecen retratados en la carta de suicidio de Perfume, niega. Seguimos sin poder añadir más datos sobre este asunto a los reunidos en nuestro artículo. Allí ya reconocíamos la falta de documentación que confirmase tal conspiración. Tan solo alusiones veladas o datos indirectos nos permitían aventurar que, efectivamente, algo de lo narrado en la nota de suicidio pudo tener lugar. Por otro lado, es natural que Bermúdez de Castro negase cualquier participación en tan espinoso asunto en el contexto de una investigación oficial. Recordemos que Juan Rey le acusaba de estar implicado en una falsa acusación, urdida contra el presunto asesino contratado por su esposa para cometer el atentado contra la vida de Guergué ("Grupo de investigación La Tribuna" 2010/2011: 26-29, 35-36).

El octavo documento es un oficio, de julio de 1848, del ayuntamiento de Aranga dirigido a José Bermúdez de Castro en concepto de curador de José Pardo Bazán. Joaquina Mosquera había adquirido bienes desamortizados en ese ayuntamiento ("Grupo de investigación La Tribuna" 2010/2011: 31, n. 60 y 61) cuyos pagos se realizaban a plazos. José Bermúdez contesta informando que los bienes de la madre del menor todavía se hallaban intervenidos por la autoridad judicial militar (recordemos que esta abrió una investigación por haber sido militar Juan Rey) y no se habían hecho las partijas entre los herederos de doña Joaquina, es decir, José Pardo Bazán y Adelaida Rey.

El último documento transcrito es una carta de José Pardo Bazán a los albaceas testamentarios de su abuela materna, doña Joaquina Ribera, fallecida el 3 de junio de 1849. En el reparto de sus bienes estuvieron, por supuesto, don José Pardo Bazán y doña Adelaida Rey Mosquera, como hijos de Joaquina Mosquera.

\section{BIBLIOGRAFÍA}

"Grupo de investigación La Tribuna" (2010/2011): "La trágica muerte de Joaquina Mosquera Ribera, abuela de doña Emilia. Un secreto familiar desvelado", en La Tribuna. Cadernos de Estudos da Casa-Museo Emilia Pardo Bazán, núm. 8, pp. 15-56.

Odriozola Rico-Avello, Carlos de (2005-2006): “Los Aldao, Bermúdez de Aldao y Bermúdez de Castro, señores de la fortaleza de Gondar", en Anales de la Real Academia Matritense de Heráldica y Genealogía, n. 9, pp. 123-228. 


\section{EDICIÓN DE LOS DOCUMENTOS PROCEDENTES DEL ARCHIVO DE DON CARLOS DE ODRIOZOLA RICO-AVELLO (MADRID)}

\section{DOCUMENTO 1}

\section{Carta de José Pardo Bazán a José Bermúdez de Castro y borrador de la respuesta de este ${ }^{8}$ (30-XI/XII-}

1847).

Querido tío: recibí la de usted de ayer, desgraciadamente ella me afirma más en mi modo de pensar, respecto a la mala fe con que obran, y conozco que me autorizan a pagar en la misma moneda.

Desde el principio de esta cuestión se me ocurrió poner fin a ella con el casamiento, y esto es lo que desde entonces me hace cavilar, y que yo hubiera hecho a no ser usted que al encargarse de la curadoría, me libró de hacerlo impremeditadamente, favor que nunca olvidaré y que me hace considerarle a usted como mi segundo padre; sin embargo una idea me atormenta, y es la de que puedo morir sin hijos (en cuyo caso ya sabe usted quien me hereda) esta idea y no la puedo desechar y es la que me decide por fin a casarme, sobre lo que tengo a mi ida a esa que consultarme largamente con usted.

Dentro de quince o veinte días estaré en esa: Guergué me escribe sobre el archivo y yo le contesto que lo haré a usted sobre el particular, y así me parece que una vez que tan poco tiempo falta para mi llegada a esa que dejemos esto hasta entonces, pues no quiere no obrar sin mí.

Ya sé por Paco el buen éxito que tuvo el viaje de Pepito lo que ha sido una satisfacción para mí.

Mil cosas a la madrina y demás familia y usted sabe le quiere su sobrino

José María

Coruña diciembre de 1847. Querido Pepe: me enteré de la tuya de 30 del pasado y supuesto piensas venir pronto hablaremos lo mismo que de tu casamiento, que es cosa muy delicada. Respecto a los asuntos de tu madre seguimos lo mismo sobre los alimentos que ha pedido, herencia de tu hermano y demás que quería mezclar en el asunto principal, lo perdió pero se le manda que reclame por - pasado; y respecto a la entrega que yo pido por inventario dice que tú te apoderaste de ellos, de la casa de Meirás y demás y aunque andamos en estas contestaciones este es asunto que ganará ella pero tiene --- tuyo y tanto por esto, como por lo enrollado que están las rentas, formación de libros cobradores y demás que es menester hacer en la casa es indispensable recoger los papeles, hacer inventario y demás que nuestra visita zanjaremos y así necesito me digas cuando vienes pero yo tengo que ir a - y hay que calcular cuándo vienes. Todos seguimos buenos y Pepe llegó el 30 y con cariños de todos ya sabes que te quiere tu tío.

\footnotetext{
${ }^{7}$ En nuestra edición regularizamos la ortografía de los textos.

${ }^{8}$ El borrador de la contestación se halla al pie del verso de la hoja de la carta remitida por don José Pardo. El papel lleva el membrete caligráfico "JPB".
} 


\section{DOCUMENTO 2}

\section{Carta de José María García ${ }^{9}$ (4-V-1848).}

Mayo 4 de 1848

Mi amigo: Rey Carús acaba de degollar a su señora y él se tiró de que está muriendo. Toda la casa es un barullo a pesar de que hemos procurado el que la justicia ponga todo en seguro. Por lo que y por lo que a Pepito $^{10}$ pueda interesar hago propio para que usted se presente en esta al momento. Martínez ${ }^{11}$ acaba de hacer otro al señor de Bermúdez.

De usted por amigo Besa La Mano

José María García

\section{DOCUMENTO 3}

\section{Carta de Celestino Martínez del Río ${ }^{12}$ a José Bermúdez de Castro (5-V-1848).}

Señor don José María Bermúdez

Muy señor mío y de mi mayor aprecio; recibo la favorecida de usted y por ella veo la confianza con que se digna honrarme, y suponiendo el fatal estado de su familia, me veo obligado, o mejor, me creo en el deber de corresponder a esa misma confianza y a la que me dispensaba su señora hermana la doña Joaquina.

Entiendo que deben oficiarse aquí las funciones de inhumación; las de séptimo día y cabo de año las dispondrán ustedes en donde les acomode; y pienso que se observe una completa igualdad en las de marido y mujer ya por la opinión pública, ya sobre todo por el decoro de la familia de esta, a la cual pertenece también una niña que lleva su apellido.

Pero el cura $^{13}$ se opone a dar a Rey sepultura eclesiástica y este Comandante Militar ofició hoy con el General participándole esta negativa, para saber cómo debe obrar. La conducta del cura es contradictoria; puesto que un excusador dio la absolución y administró la unción al Rey, después de la cual vivió todavía tres horas. Esta última circunstancia la niega ahora el cura y nada más fácil hay que acreditarlo con testigos. Se omitió participarla al General, según acabo de saber de boca del mismo Comandante. Comprendo que debe sostenerse la inhumación en el cementerio, ya porque no está contiguo a la iglesia y no puede considerarse lugar sagrado, sino religioso, ya porque debe suponerse que un suicida obra en virtud de un acto de furor, ya porque la benignidad de la iglesia admite a los entredichos a las funciones mayores con sola la prohibición de acercarse al altar, o ya en fon porque la absolución sub conditione supone perdón o remisión del hecho pecaminoso y por consiguiente el arrepentimiento.

$\mathrm{Si}$, pues, necesaria fuese justificación de esos actos religiosos administrados a Rey, se puede hacer, no por él precisamente, sino por su hija tierna. Todavía no calmó la impresión que ha causado este suceso a su atento amigo y Servidor que Besa La Mano

Celestino Martínez del Río

Contesto en casa de Couceiro ${ }^{14}$ que me manifiesta diga a usted tenga esta por suya.

\footnotetext{
${ }^{9}$ Procurador en el juzgado de Betanzos, llevó para Joaquina Mosquera el pleito que esta tuvo con su hijo por su curadoría.

${ }^{10}$ Se refiere a don José Pardo Bazán.

${ }^{11}$ Se trata de Celestino Martínez del Río.

${ }^{12}$ Natural de A Coruña aunque su familia procedía de Betanzos. Estudió derecho en la Universidad de Santiago de Compostela, de la que llegó a ser rector entre 1855 y 1856. Doña Joaquina Mosquera lo nombró su apoderado en 1847 y fue, además, su procurador en los pleitos que mantuvo con su hijo entre 1847 y 1848 ("Grupo de investigación La Tribuna" 2010/2011: 27, n. 52).

${ }^{13}$ Su nombre era Manuel Saldos Recuero ("Grupo de investigación La Tribuna" 2010/2011: 50)

${ }^{14}$ José Manuel Couceiro, vecino de Betanzos y administrador en la ciudad de bienes pertenecientes a la familia Pardo Bazán ("Grupo de investigación La Tribuna" 2010/2011:38).
} 


\section{DOCUMENTO 4}

Carta de Andrés Perfumo ${ }^{15}$ a José Bermúdez de Castro (7-V-1848).

Señor don José María Bermúdez de Castro

Betanzos mayo 71848

Muy señor mío: desde que he llegado con este Tribunal de Guerra hemos dado todos los pasos oportunos con este cura de Santiago para hacer las exequias que corresponden, el que se ha negado enteramente a enterrar en sagrado mi sobrino, bajo este supuesto se copiaron todos los oficios y comunicaciones con un oficio muy relevante al señor arzobispo de Santiago que remití en posta a las dos de la noche del 6 y ha llegado a las 4 de la mañana de hoy con la contestación, en la que manifiesta que siendo el caso tan urgente y transcendental delega sus facultades al cura y juez eclesiástico don Roque Paz para que delibere, al momento fui a casa del dicho cura para enseñarle esta comunicación particularmente con orden del señor auditor que eran las 5 de esta mañana, el que no quiso resolver sin oír al cura párroco de Santiago, al momento el señor asesor le pasó esta comunicación por medio de un oficio para que en el término de una hora resolviese sobre el particular, el que a las 8 contestó por medio de un oficio escandaloso negándose dar sepultura eclesiástica a mi sobrino, el señor auditor se puso furioso y mando en el acto a la guardia civil para que fuese a la casa del cura de Santiago y se pusiese a su misma presencia para que no se separase de su lado afín de que no se ocultase mandó al mismo tiempo a los facultativos para que a las 9 se le hiciese la autopsia a los dos cadáveres y luego se les dará sepultura en sagrado con oposición de estos malvados sacerdotes que me ponen en el caso de desesperación después de lo ocurrido, pues no se puede tolerar un escándalo igual. El auditor está furioso y me manifestó que aun que supiera de perder su destino, no cesará de llevar el caso adelante, yo me hallo en un estado capaz de hacer un disparate con este cura autor de todos estos trastornos, pero después de lo ocurrido me contengo. Hago a usted esta breve narración para que sepa lo ocurrido y me dispensará si digo algún disparate porque mi cabeza no está para nada, y se repite.

Es de usted su atento Seguro Servidor que La Mano Besa

Andrés Perfumo

\section{DOCUMENTO 5}

Carta de Celestino Martínez del Río a José Bermúdez de Castro, a la que acompaña otra para el mismo José Bermúdez, firmada por Celestino Martínez, Luis María Guergué, José Manuel Couceiro y José María García (7/9-V-1848).

Señor don José María Bermúdez

Betanzos 9 de mayo de 1848

Muy señor mío y de toda mi consideración; creo haber ultimado nuestra misión, sino con el tino que deseáramos, al menos con la mejor y más decidida voluntad. Terminó hoy el inventario, en el cual, como en todo lo demás, se condujeron el señor Auditor y señor Fiscal con el mayor celo, deferencia hacia nosotros, y hasta si se quiere, con excesiva pureza; se hicieron acreedores a nuestra gratitud y son dignos de que se les den las más expresivas gracias.

El señor Romay quedó depositario de todo lo inventariado y no tuvo el menor reparo en entregarnos las llaves. A su vista se sacaron de la cómoda los 6.070 reales hallados en uno de sus cajones que se entregaron a Guergué para que este lo haga a usted; dejó recibo a dicho depositario que entiendo deba cancelarse por otro de usted. Se sacaron además 40 reales, 8 maravedís que estaban en calderilla y se entregaron a la

${ }^{15}$ Tío de Juan Rey Perfume, fue comisario de Betanzos. Trabajó para los Mosquera como apoderado, siendo nombrado albacea testamentario por Joaquina Mosquera (“Grupo de investigación La Tribuna” 2010/2011: 23-24, 38). 
doncella para el gasto de casa. Se sacó también la plata que se trasladó a casa del mismo señor Romay para mayor seguridad.

Hemos ajustado los criados sus soldadas y les fueron satisfechas esta misma noche, diéronseles lutos nuevos a la doncella, porque no habiendo aquí más de una tienda que lo tuviese de la clase que ella requería, intentaba la tendera aprovechar la ocasión y resolvimos que ustedes se lo diesen en esa o hiciesen lo que mejor les pareciese: mañana despediremos el servicio, y entregaremos a Romay la llave de la casa.

Esta devenga una renta de 4 reales diarios que considero urgente evitar. Para ello es preciso llevar de aquí los muebles o a esa o a Meirás, dejando al expuesto Romay recibo y dando orden a Couceiro para que pague el alquiler de la casa por el tiempo corrido desde que lo han satisfecho los finados, que me parece ha sido en marzo o abril últimos.

Habemos [sic] formalizado una relación de los más gastos ocurridos por virtud de tan lamentable suceso, y se gratificó a los soldados que guardaron la casa 40,20 reales a cada uno de ellos; Guergué llevará aquella.

Pasé ayer a verme con el cura para que dispusiese los oficios de entierro de marido y mujer y se negó a hacer los del primero, como usted verá por la adjunta certificación, que remito conforme al encargo de usted. Queda esperando sus órdenes y ocasiones en que manifestarle su consideración, pero jamás igual ni parecida remotamente a la presente, su atento amigo y Servidor que La Mano Besa

Celestino Martínez del Río

Señor don José María Bermúdez ${ }^{16}$

Betanzos 7 de mayo de 1848

Muy señor nuestro y de nuestra mayor consideración; ya se halla usted informado de la negativa de este párroco a dar sepultura eclesiástica al cadáver de Rey, y de la comunicación de este señor Auditor al arzobispo que la contestó facultando al juez eclesiástico de esta don Roque Antonio Paz para que resolviese; y acaba de hacerlo negativamente. Apurados los medios de conciliación ya se hizo forzoso recurrir a los violentos y dicho señor Auditor determinó se dé a ambos cadáveres sepultura en el cementerio y que si el cura por sí o medio de otro resistiese presidir la conducción de aquellos, se le obligue por medio de la fuerza. En este estado de cosas creímos oportuno suspender las funciones de entierro y participárselo a usted a fin de que se sirva disponer lo que deba hacerse, advirtiendo que a esta misma hora está dispuesta la conducción y aptosia en el camposanto. Quedan esperando sus órdenes sus atentos amigos y Seguros Servidores que Besan La Mano

Luis María Guergué

Celestino Martínez del Río

Couceiro

José María García

\footnotetext{
${ }^{16}$ Se le contestó el mismo día diciéndole: que ya que por las por las ocurrencias del cura no se habían hecho las funciones de cuerpo presente, se verificasen mañana, y si se acostumbraba hacer de segunda la de honras, se ejecutase también; por lo demás ya se determinaría que si el cura se oponía a hacerlas se sacase un certificado para acudir a donde convenga.
} 


\section{DOCUMENTO 6}

Carta de Luis María Guergué a José Bermúdez de Castro (1-V-1848).

Señor don José María Bermúdez

Meirás mayo 11 de 1848

Muy señor mío: las desgracias acaecidas me han afectado sobre manera y a consecuencia de ello estoy padeciendo fuertes dolores de cabeza y me hallo en cama por lo que me es imposible pasar hoy a esa. Ayer concluimos nuestras operaciones en Betanzos y por la mañana acabamos de formalizar nuestra cuenta, la que se halla en mi poder como también seis mil setecientos reales por un lado y 40 con 8 maravedíes por otro que hallándome mejor entregaré a usted mañana. El señor Martínez y demás me han encargado diga a usted esté a la vista porque no cargue el Tribunal las costas sobre la herencia. Sin más hoy me alegraré sigan ustedes todos buenos y mande a su afectísimo Servidor que Besa La Mano

Luis María Guergué

\section{DOCUMENTO 7}

\section{Copia simple de declaración de José Bermúdez de Castro.}

Dijo: que tuvo muy cortas relaciones con don José Rey Perfume; sin embargo por algunas conversaciones que mediaron entre ambos con motivo de la transacción sobre los intereses de su menor don José Pardo Bazán conoció era de un carácter violento y demasiado susceptible, altivo y orgulloso en extremo especialmente tratándose de lo que equivocadamente llamaba su honor. Que estos antecedentes y la lectura del papel que Rey dejó escrito le convencen y cree convencerán a cualquiera de que los horrores de que informa el mismo son producto de una enajenación mental. Que no puede atribuir a otra cosa la idea de la conspiración de que habla de la que ni es ni remotamente tiene idea ni puede concebirse en ningún sentido. Que es verdad que en Meirás en una de sus conversaciones con motivo de la indicada transacción Rey le habló de la delación que indica pero tal era el estado de exaltación en que se encontraba ya por sus ideas exageradas ya por hallarse aquel día algo cargado de bebida que no pudo formar el que contesta juicio de lo que le dijo ni dar más razón sobre el particular. Por último que aunque por los intereses de su menor estaba en pleito con su cuñada y por consiguiente la trataba poco o nada, cree que en el matrimonio había ya disturbios procedidos de las causas que deja indicado. 


\section{DOCUMENTO 8}

\section{Oficio del ayuntamiento de Aranga a José Bermúdez de Castro y borrador de la contestación de este ${ }^{17}$} (11, 15-VII-1848).

Teniendo noticia esta corporación, ser usted el representante del señor hijo de doña Joaquina Mosquera de Pardo Bazán ahora difunta, le remite el adjunto aviso de lo que corresponde satisfacer por razón de anticipación reintegrable de 100 millones de reales, esperando que usted en el plazo prefijado de los diez días que se marcan se digne hacer su entrega en esta depositaría o remesar por el dador los 1,70 reales con que le corresponden por tal concepto con descuento ya del 6 por ciento de negociación, en la inteligencia que se le expedirá recibo oportuno y documentos de los establecidos; de cualquier manera espero su aviso y contestación.

Dios que a Usted Mande Salud

Aranga julio 111848

Félix Maseiras

Señor don José María Bermúdez

Contestando a su oficio de fecha 11 del corriente en que me incluye la papeleta que marca la nota que en el anticipo reintegrable de 100 millones, han cargado a la difunta doña Joaquina Mosquera y que usted me ha dirigido creyendo que como curador del hijo de aquella don José María Pardo Bazán me hallo en el caso de satisfacer; debo decir a usted que mi curadoría solo se entiende con respecto a los bienes de dicho menor heredados por su padre, pues con respecto a lo que le pueda corresponder por dicha señora nada absolutamente administro hasta ahora por hallarse todo lo perteneciente a la referida en poder del Juzgado de Guerra sin haberse hecho por ahora la partija, ni menos nombrado curador a la niña que quedó del segundo matrimonio de aquella señora; por consiguiente solo con aquel juzgado puede entenderse, devolviéndole la citada papeleta o aviso.

Dios que a Usted Mande Salud

Coruña julio 151848

Señor alcalde constitucional de Aranga

\section{DOCUMENTO 9}

\section{Carta de José Pardo Bazán a los albaceas de doña Joaquina Ribera (24-VI-1849).}

Señores testamentarios de la herencia de la señora doña Joaquina Ribera y Pardo

Sanjenjo 24 de junio de 1849

Muy señores míos: es en mi poder la de ustedes fecha 21 de este, a la que debo contestar que en atención a las circunstancias que en ustedes se reúnen desempeñarán con la mayor inteligencia e interés el inventario de los bienes de mi señora abuela (Q....) y por consiguiente inútil es mi presencia en esa, delegando mi representación en ustedes y aprobando desde ahora todo lo que en este concepto puedan verificar.

Es de ustedes con la mayor consideración su atento y Seguro Servidor que Besa La Mano

José Pardo Bazán

\footnotetext{
${ }^{17}$ El borrador de la contestación se escribió aprovechando el margen izquierdo del oficio, que como es norma en estos documentos se presenta siempre en blanco, ocupando el texto del mismo únicamente el margen derecho.
} 